\title{
Perancangan Jaringan Pada Client - Server Menggunakan Aplikasi Cisco Paket Tracer
}

\author{
Bayu Kurniawan'), Yuyantofa ${ }^{2)}$ \\ Program Studi Teknik Informatika Fakultas Ilmu Komputer Universitas Lancang \\ Kuning \\ Jl. Yos Sudarso KM. 8 Rumbai, Pekanbaru, Riau, telp. 08117532015 \\ e-mail: bayu.k18999@gmail.com, yuyantofa@gmail.com
}

\begin{abstract}
Abstrak
Koneksi jaringan komputer merupakan suatu hal yang mendasar dalam suatu jaringan karena bila koneksi bermasalah, maka semua jenis aplikasi yang dijalankan melalui jaringan komputer tidak dapat digunakan. Cisco Packet Tracer dapat digunakan untuk simulasi yang mencerminkan gambaran dari koneksi jaringan komputer pada sistem jaringan yang digunakan. Paper ini merancang dua buah perancangan, yakni perancangan dengan topologi Star dari satu server menggunakan software Cisco Packet Tracer dan menghubungkanjaringan antar komputer. Hasil penelitian ini adalah terhubungnya antar jaringan komputer.Kajian ini dilakukan untuk mengetahui apakah komputer server dan client bisa saling berkomunikasi.
\end{abstract}

Kata kunci: Cisco Packet Tracer, Topologi star

Abstract

Computer network connection is a fundamental thing in a network because if a connection is problematic, then all types of applications that run through a computer network cannot be used. Cisco Packet Tracer can be used for simulations that reflect a picture of the computer network connection on the network system used. This paper designs two designs, namely the design with a star topology from one server using Cisco Packet Tracer software and connecting networks between computers. The results of this study are the connection between computer networks. This study was conducted to find out whether the server and client computers can communicate with each other

Keyword : Cisco Packet Tracer, Topologi star 


\section{Pendahuluan}

Jaringan komputer adalah perpindahandata (Komunikasi Data) dari suatu computer sumber (transmiter) ke komputer tujuan (receiver) yang melewati suatu media pengantar dalam bentuk bit-bit. Salah satu contoh dari jaringan komputer adalah video conference pada komputer, dimana suara video yg dihantar harus diolah dalam bentuk bit-bit sebelum memasuki media penghantar untuk di komunikasikan (Stalling, 2015).

Cisco Packet Tracer adalah simulator alat-alat jaringan cisco yang sering digunakan sebagai media pembelajaran dan pelatihan, dan juga dalam bidang penelitian simulasi jaringan komputer. Program ini dibuat oleh Cisco Systems dan disediakan gratis untuk fakultas, siswa dan alumni yang telah berpartisipasi di Cisco Networking Academy. Tujuan utama cisco paket tracer adalah untuk menyediakan alat bagi siswa dan pengajar agardapat memahami prinsip jaringan komputer dan juga membangun skill di bidang alat-alat jaringan Cisco.

Jaringan komputer bertugas supaya terbebas dari masalah seperti pengiriman data yang lambat, koneksi yang tidak stabil, dan sebagainya sehingga secara tidak langsung dapat mengurangi produktivitas kerja. Koneksi jaringan komputer merupakan suatu hal yang mendasar dalam suatu jaringan, karena bila koneksi itu bermasalah maka semua jenis aplikasi yang dijalankan melalui jaringan komputer tidak dapat digunakan. Mengingat kebutuhan akan informasi jaringan komputer begitu penting terutama untuk mencari kerusakan jaringan secara cepat, mudah, dan murah, maka untuk mengatasi masalah diatas seorang administrator jaringan memerlukan. aplikasi Network Monitoring System untuk simulasi yang dapat mencerminkan arsitektur dari jaringan komputer pada sistem jaringan yang digunakan. Ada banyak software yang dapat digunakan dalam simulasi jaringan komputer.

\section{Analisa Masalah}

Dalam melakukan analisa masalah peneliti melakukan beberapa-beberapa metode diantaranya adalah metode diskriptif, dalam metode ini dilakukan pengumpulan data, kemudian disusun, dikelompokkan, dianalisa sehingga diperoleh beberapa gambaran yang jelas pada masalah penelitian. Sehingga dari analisa masalah tersebut dapat ditarik suatu kesimpulan untuk mendapatkan suatu solusi penyelesaian masalah (Yogi Yunefri, 2015:55).

1. Menentukan Tujuan Penelitian

Berdasarkan pada ruang lingkup masalah, analisa masalah yang telah dibuat pada tahap sebelumnya, tahap berikutnya adalah menentukan tujuan penelitian yang bertujuan untuk memperjelas kerangka tentang apa saja yang menjadi sasaran dari penelitian ini.

\section{Mempelajari Literatur}

Tahap selanjutnya adalah mempelajari literatur, jurnal, buku-buku yang berhubungan dengan penelitian. 


\subsection{Pengumpulan Data}

Pengumpulan data dan informasi pada tahap ini dilakukan untuk mendapatkan data dan informasi yang nantinya akan mendukung penelitian ini, dalam pengumpulan data, terdapat beberapa metode yang digunakan yaitu penelitian Lapangan (field reseach), penelitian perpustakaan(Library reseach), serta penelitian laboratorium (Laboratory Reseach) (Yogi Yunefri, 2015:55).

a. Penelitian lapangan (field research)

Penelitian lapangan yang dikenal juga dengan field research merupakan penelitian yang dilakukan untuk mendapatkan data yang spesifik dan real Mengenai perancangan jaringan pada client-server.

b. Penelitian perpustakaan

Penelitian ini dilakukan untuk melengkapi pembendaharaan kaidah, konsep, teori dan lain lain.Penelitian ini juga dilakukan melalui buku-buku, jurnaljurnal, majalah-majalah yang maupun referensi yang lain. Penelitian ini ditujuakan untuk mengumpulkan data, baik data primer maupun data skunder, dimana semua data tersebut sangat dibutuhkan dalam penelitian ini.

c. Penelitian laboratorium (laboratory research)

Penelitian laboratorium ini dimaksud untuk melakukan pengujuian terhadap perancangan . Pada penelitian laboratorium ini tidak lepas dari piranti atau perangkat yang digunakan, dimana perangkat ini dapat digunakan untuk membantu penulis melakukan pengujian. Adapun perangkat yang digunakan adalah :

a) Perangkat keras, perangkat itu terdiri dari :

- Satu unit laptop

- Hardisk 320 GB

- Dan beberapa perangkat keras pendukung lainnya.

b) Perangkat lunak, perangkat lunak ini terdiri dari :

- Sistem Operasi Microsoft Windows 7

- Cisco Packet Tracker

- Dan beberapa pendukung perangkat lunak lainnya.

\section{Jaringan Local Area Network (LAN)}

Jaringan LAN merupakan jaringan milik pribadi didalam sebuah kantor, gedung atau kampus yang berjarak sampai beberapa kilometer. LAN seringkali digunakan untuk menghubungkan komputer-komputer pribadi dan workstation dalam kantor suatu perusahaan atau pabrik-pabrik untuk memakai bersama sumber daya (resource, misalnya printer) dan saling bertukar informasi. Suatu jaringan LAN.

\subsection{Topologi Jaringan Komputer}

Topologi Star adalah topologi yang menggunakan setiap komputer melalui hub/switch. Fungsi hub/switch adalah sebagai pengatur dan pengendali dalam pengiriman ke komputer satu tanpa melewati komputer yang bukan tujuan.

Topologi ini merupakan kontrol terpusat, semua link harus melewati pusat yang menyalurkan data tersebut kesemua simpul atau clientyang dipilihnya. Simpul pusat dinamakan stasiun primer atau server dan lainnya dinamakan stasiun sekunder atau client server. Setelah hubungan jaringan dimulai oleh server maka 
setiap client server sewaktu-waktu dapat menggunakan hubungan jaringan tersebut tanpa menunggu perintah dari server. Gambar 1 adalah gambar dari topologi star

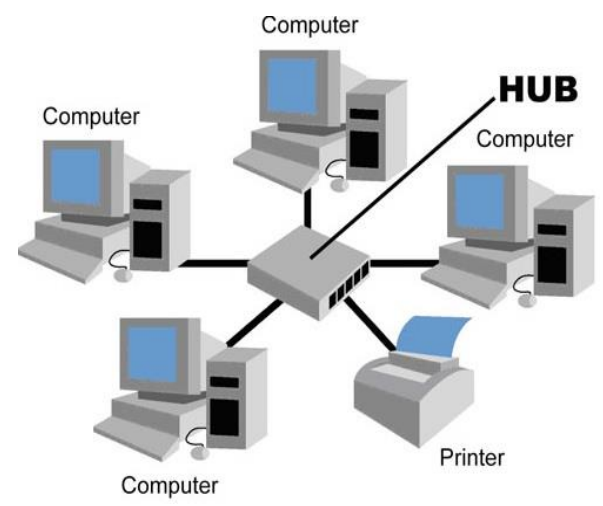

Gambar 1. Topologi Star

Tabel 1 Kelebihan dan Kekurangan Topologi star

\begin{tabular}{|c|c|}
\hline Kelebihan & Kekurangan \\
\hline $\begin{array}{l}\text {-Paling fleksibel } \\
\text {-Pemasangan/perubahan stasiun sangat } \\
\text { mudah dan tidak mengganggu bagian } \\
\text { jaringan lain } \\
\text {-Kontrol terpusat } \\
\text {-Kemudahan deteksi dan isolasi } \\
\text { kesalahan/kerusakan } \bullet \text { Kemudahaan } \\
\text { pengelolaan jaringan }\end{array}$ & $\begin{array}{l}\text {-Boros kabel } \\
\text {-Perlu penanganan khusus } \\
\text {-Kontrol terpusat (HUB/Switch) } \\
\text { jadi elemen kritis }\end{array}$ \\
\hline
\end{tabular}

\section{Perancangan Jaringan dengan Menggunakan Cisco Packet Tracer} Menurut Dafwen Toresa (2017:54) Gambar rancangan Jaringan Proxy Server adalah sebagai berikut :

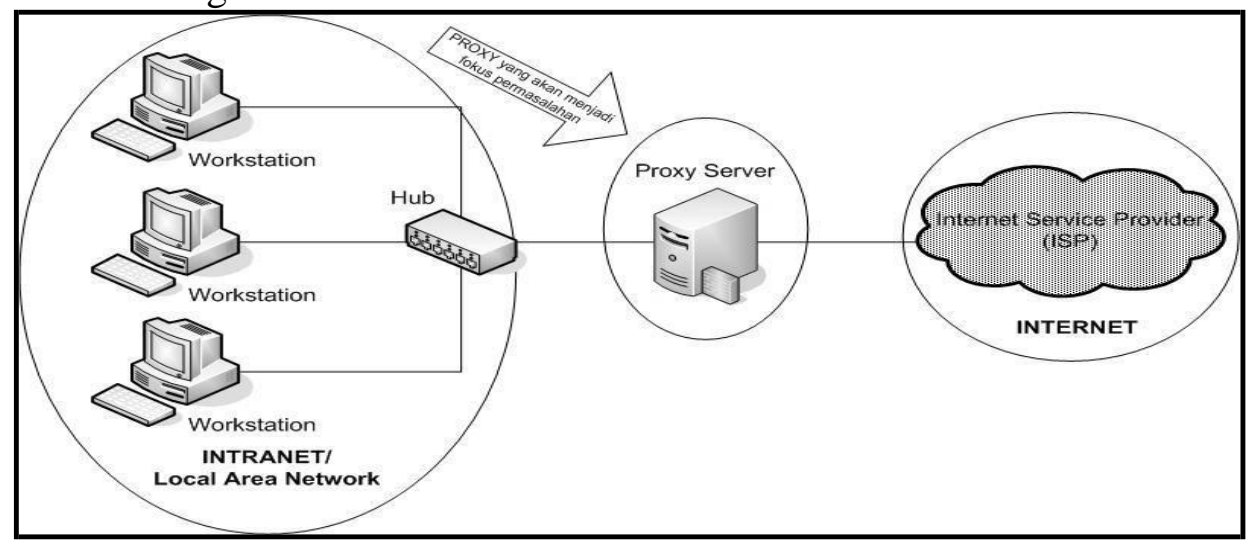

Gambar 2. Rancangan Jaringan 
Persiapan perancangan jaringan dilakukan dengan mengasumsikan menggunakan 3 buah switch, 21 komputer, dan 1 server. Masing-masing switch terhubung dengan 7 komputer. Dan setiap komputer tersebut mempunyai IP address dengan level dan kelompok yang sama. Untuk membuat model jaringan komputer yang akan digunakan bisa dilakukan dengan memanfaatkan area kerja dari Cisco Packet Tracer. Peralatan yang digunakan dapat dipilih dari kolom pemilihan jenis alat dan koneksi yang berada di sebelah kiri bawah. Hasil dari model jaringan yang dibuat dapat dilihat pada Gambar 3.

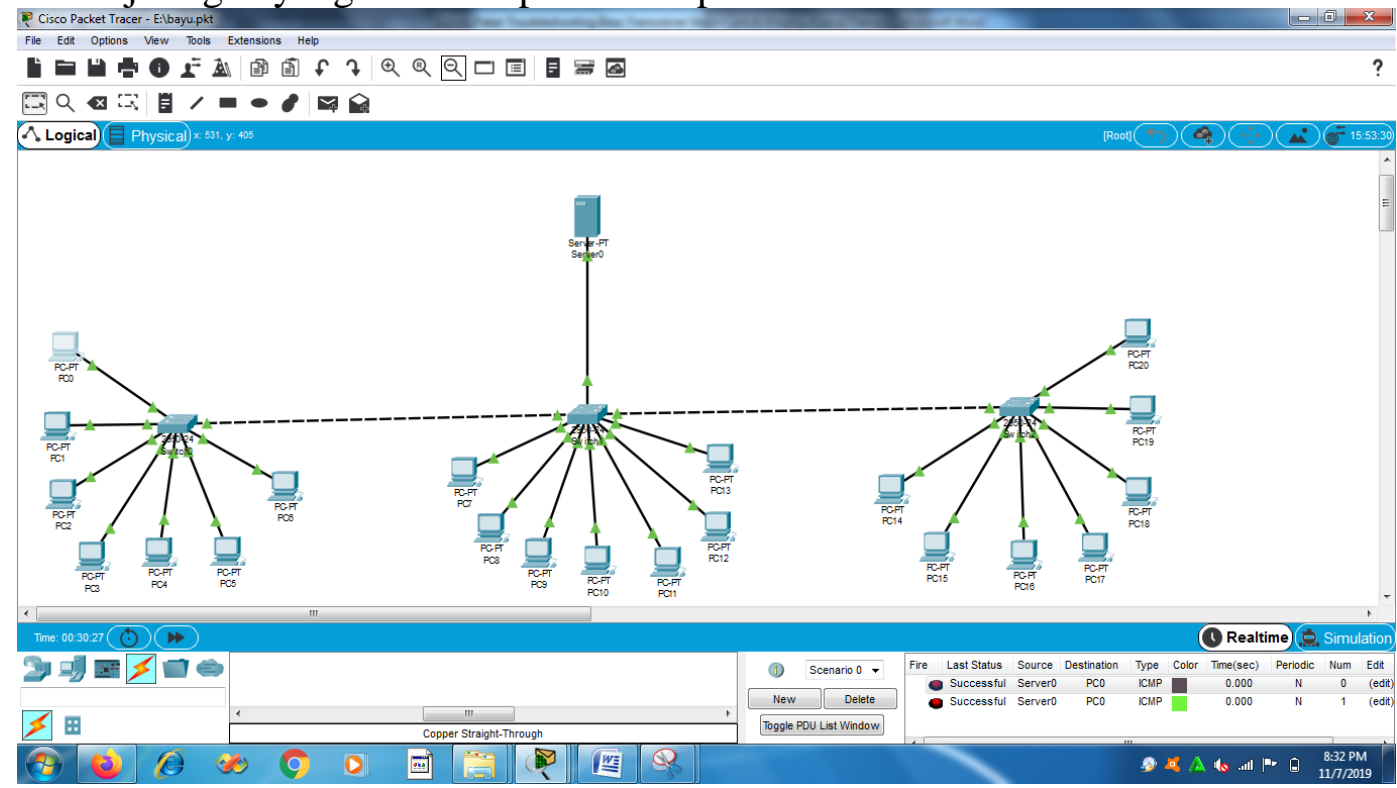

Gambar 3. Tampilan perancangan cisco packet tracker

\subsection{Pengisian IP Address}

Dalam perancangan ini akan didefinisikan terlebih dahulu berapa IP untuk masing-masing PC yang digunakan pada masing-masing gedung. Untuk mengisi IP Address dengan cara klik pada PC yang ingin diberi IP address, lalu pilih desktop, setelah itu pilih IP configuration, kemudian masukkan nomor IP Address,

Setelah semua komputer sudah dikonfigurasi IP Addressnya, sekarang waktunya untuk mencari tahu apakah jaringan sudah terbentuk sempurna atau belum, dengan cara mengkonfigurasi komputer yang berseberangan. 


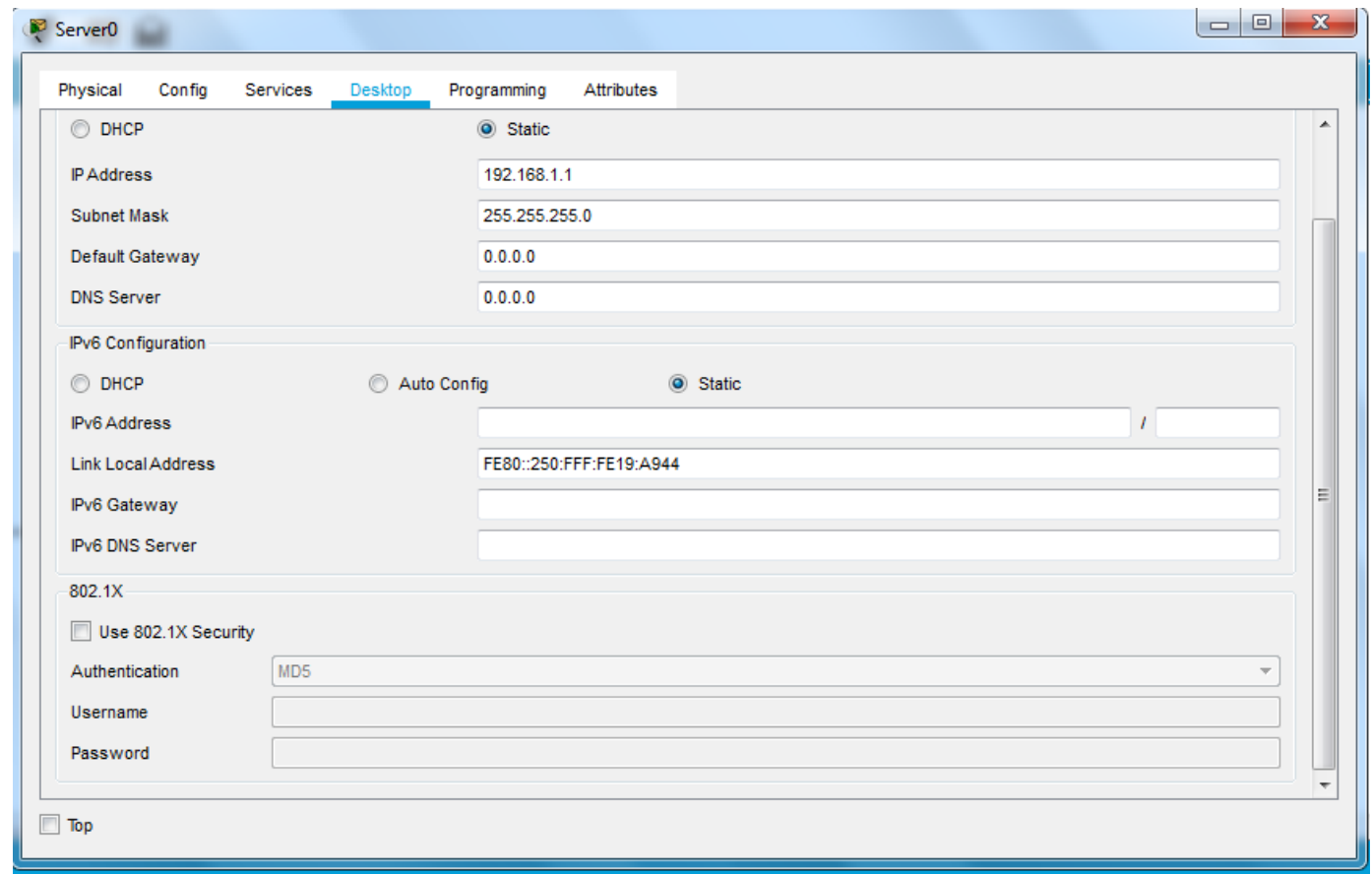

Gambar 4. Pengisian Ip Address pada Server.

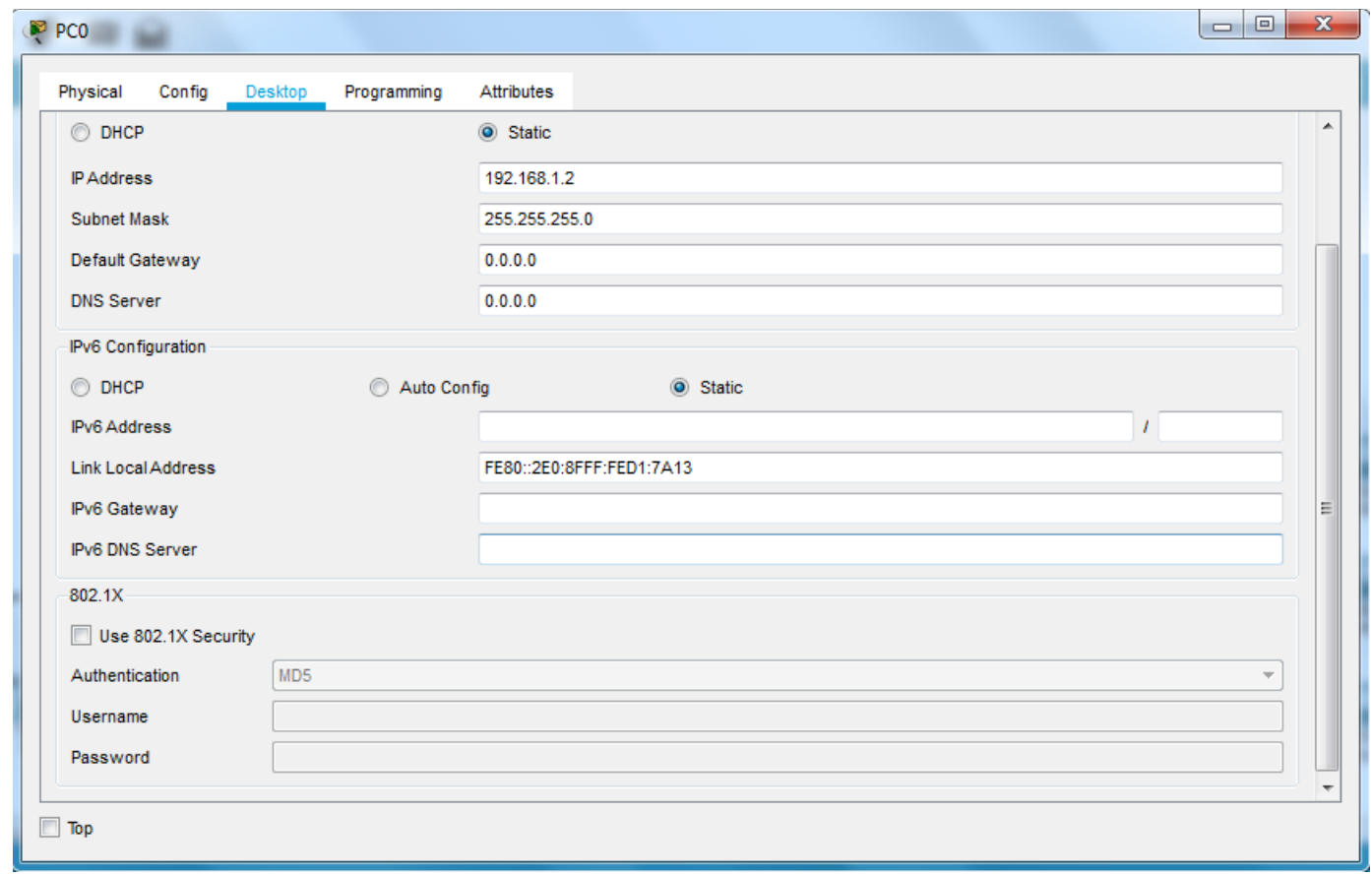

Gambar 5. Pengisian IP Address pada Komputer

\section{Hasil Perancangan}

Setelah semua komputer sudah dikonfigurasi IP Addressnya, sekarang untuk mencari tahu apakah jaringan sudah terbentuk sempurna atau belum, dengan cara menge-ping komputer yang berseberangan. 
1. Klik komputer yang ingin meng-ping komputer lain, kemudian akan muncul window baru,

2. Klik tab Desktop,

3. Masuk ke menu Command Prompt,

4. Dan ketikkan ping ke komputer tujuan

5. Ping sukses menandakan jalur komunikasi data antar 2 perangkat tersebut sudah terhubung dan siap digunakan, seperti gambar 4 .

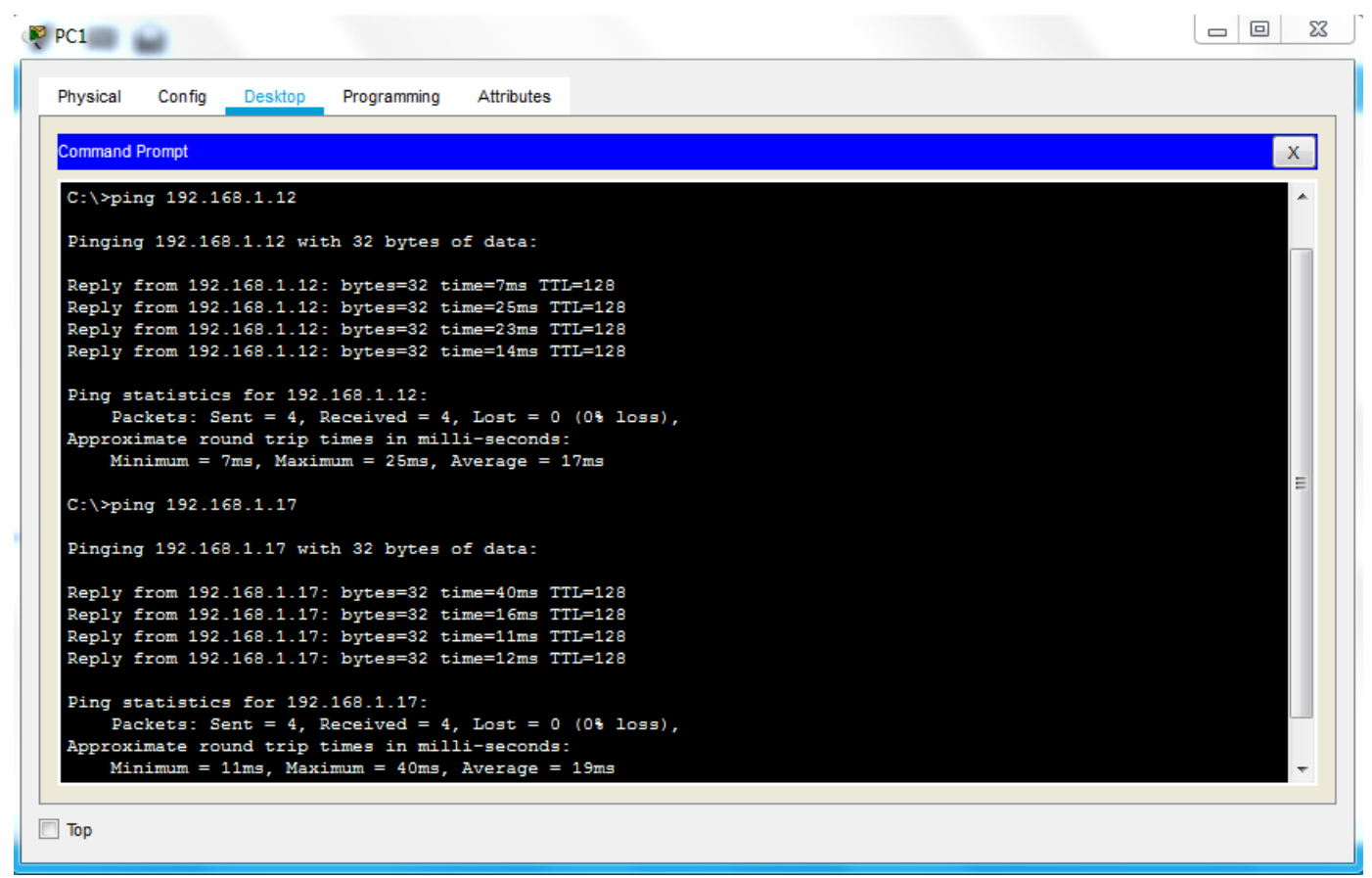

Gambar 6. Mengkoneksikan komputer ke komputer lain

Gambar berikut diambil berdasarkan PC yang menjadi transmitter dan PC lainya sebagai receiver.

\begin{tabular}{|rccccccccc|} 
Fire Last Status & Source & Destination & Type & Color & Time(sec) & Periodic & Num & Edit \\
\hline Successful & PC2 & PC10 & ICMP & 0.000 & N & 0 & (edit) \\
\hline Successful & PC6 & PC12 & ICMP & 0.000 & N & 1 & (edit) \\
Successful & PC20 & PC0 & ICMP & 0.000 & N & 2 & (edit)
\end{tabular}

Gambar 7. Mengirim informasi dari komputer ke komputer lain 


\section{Kesimpulan}

1. Jaringan Local Area Network dirancang menggunakan software Cisco Packet Tracer, menggunakan 21 komputer, 3 switch, 1 server

2. Berdasarkan hasil untuk setiap pengujian pada perancangan menggunakan Cisco Packet Tracer setiap komputer bisa terhubung satu sama lain dan bisa mengirim pesan satu sama lain.

\section{DAFTAR PUSTAKA}

1. Dafwen Toresa, 2017" Perbandingan proxy pada linux dan windows untuk mempercepat browsing website", Pekanbaru : Jurnal Teknologi Informasi \& Komunikasi Digital Zone

2.Yogi Yunefri, 2015." Sistem Pakar Troubleshooting Base Transceiver Station untuk Efisiensi Kinerja Teknisi (Studi Kasus: PT. KMS TELECOM PEKANBARU)”, Pekanbaru : Jurnal Teknologi Informasi \& Komunikasi Digital Zone 